\title{
Deficit Irrigation in Vitis labruscana Bailey 'Concord' in Central Washington
}

\author{
Jason E. Stout and Joan R. Davenport ${ }^{1}$ \\ Department of Crop and Soil Sciences, Irrigated Agricultural Research and \\ Extension Center, Washington State University, 24106 North Bunn Road, \\ Prosser, WA 99350
}

\section{R. Troy Peters \\ Department of Biological Systems Engineering, Irrigated Agricultural Research and Extension Center, Washington State University, 24106 North Bunn Road, Prosser, WA 99350}

\section{Additional index words. crop coefficient, shaded area, evapotranspiration}

\begin{abstract}
Drought conditions in the western United States have limited water availability for the irrigation of agricultural products. This can have a dramatic impact on yield and quality of specialty perennial crops, such as juice grapes (Vitis labruscana Bailey). Washington State juice grape industry typically irrigates to $100 \%$ of crop-specific evapotranspiration (ET $_{c}$ ) throughout the season to minimize yield loss. However, as conditions have limited water availability, growers need a new strategy to cope with the limited water supply. Regulated deficit irrigation (RDI) applies less water than plant ET $_{c}$ and has been shown to improve fruit quality in red wine grapes (Vitis vinifera). The objectives of this study were to evaluate the effects of RDI treatments on the yield and quality of 'Concord' juice grapes as compared with current commercial practice. The treatments reduced the amount of water applied between bloom and veraison by $25 \%$ $(-25 \%), 33 \%(-33 \%)$, and $45 \%(-45 \%)$ from the control application. The results of this 4-year study initially indicated a dramatic decrease in yield in the $-45 \%$ treatment $(7.5 \mathrm{Mg} / \mathrm{ha})$ as compared with the control treatment $(19.2 \mathrm{Mg} / \mathrm{ha})$; however, yield for the RDI treatments recovered in the subsequent seasons and was not statically different from the control. There were no statistical differences in fruit quality between treatments. This indicates that RDI has the potential to decrease water applied between bloom and veraison without impacting fruit quality; however, to avoid a sudden decrease in yield, it would be necessary to gradually reduce water applications over several years.
\end{abstract}

In Washington State, 'Concord' grape $(V$. labruscana) production is concentrated in the Yakima Valley in Central Washington and yield is heavily dependent on supplemental irrigation because of the arid steppe climate (Fischer and Turner, 1978), which receives less than $250 \mathrm{~mm}$ of annual precipitation (Elsner et al., 2010, Fig. 1). Recently, low winter snowfall has limited the availability of surface irrigation supplies during the growing season (April to October). In 2001, the Roza irrigation district, which services the lower Yakima Valley, only delivered $38 \%$ of normal water delivery (Washington Department of Ecology, 2001). Similarly, in 2015, faced with limited irrigation supplies, the members of the Roza irrigation district voted to shut off irrigation availability for almost the entire month of June to extend their allotment later into the growing season (Washington Department of Ecology, 2015). Such decreases in available water can lead to large reductions in yield, especially when deficits occur

Received for publication 14 Oct. 2016. Accepted for publication $3 \mathrm{Feb} .2017$.

${ }^{1}$ Corresponding author. E-mail: jdavenp@wsu.edu. during critical plant developmental stages, such as bloom and fruit set (Kriedemann and Goodwin, 2003).

Previous research relating to 'Concord' irrigation strategies was largely conducted in the eastern United States, which has high rainfall and a humid environment. Morris and Cawthon (1982) and Morris et al. (1983a, $1983 b)$ have extensively studied the interaction of irrigation, pruning severity, and fertilization on 'Concord' yield in Arkansas and found that additional irrigation indirectly increased yield by increasing vine vigor. However, increased yields were inversely related to juice quality (Morris et al., 1983b).

RDI is the technique of applying less water than a plant would otherwise use during a specific period of the growing season. This technique can be used to cope with limited irrigation availability or to improve fruit quality in the case of red wine grape ( $V$. vinifera L.). However, there is little research on the impacts of RDI on 'Concord' yield and berry quality in part because RDI has the potential to limit yield and economical 'Concord' production is largely focused on yield with a minimum set of quality standards. In addition, many Concord vineyards that are irrigated use systems that do not lend themselves to RDI management (Moyer et al., 2013) and there is limited use of irrigation in 'Concord' vineyards in regions other than Washington State (Cuykendall et al., 1999).

The objective of this study was to evaluate RDI between bloom and veraison as a potential management strategy in 'Concord' production to reduce water use in response to drought conditions. Our study assessed the impact of three levels of RDI on yield, fruit quality, and seasonal soil moisture distribution.

\section{Materials and Methods}

Plot design. This study was conducted in a 10 ha commercial 'Concord' vineyard located in the Yakima Valley American Viticulture Area (Sunnyside, WA) $\left(46^{\circ} 20^{\prime} 21^{\prime \prime} \mathrm{N}\right.$ and $\left.119^{\circ} 55^{\prime} 34^{\prime \prime} \mathrm{W}\right)$ from Jan. 2011 to Feb. 2015. The vineyard was planted in 1990 on own-rooted vines with a $1.8 \mathrm{~m} \times 3 \mathrm{~m}$ spacing and a north-northeast to south-southwest row orientation. Vines were trained on a single trunk to a wire $1.8 \mathrm{~m}$ above the soil surface. The canopy sprawled from the wire and was minimally pruned. During the study, all fertilizer and disease and pest management strategies were applied by the grower based on commercial practices for high yields and applied as uniformly as possible across the vineyard (Hoheisel and Moyer, 2016).

Plots were arranged in a randomized block design with four blocks, each containing four treatments, for a total of 16 plots. Each plot consisted of a 30-m section of three rows. The two outside rows were buffer rows and the middle row served as the sample row, with samples and measurements taken from the center 10 vines. The vineyard was irrigated using drip emitters with a flow rate of $2.27 \mathrm{~L} \cdot \mathrm{h}^{-1}$ and a spacing of $0.9 \mathrm{~m}$, resulting in an application rate of $0.84 \mathrm{~mm} \cdot \mathrm{h}^{-1}$. Due to a lack of sufficient winter precipitation, irrigation was applied before or immediately following budbreak until the soil reached field capacity $(\approx 25 \% \mathrm{v} / \mathrm{v})$ (Evans et al., 1993). Soil water content of the control treatment was maintained throughout the growing season by the grower using standard practices of applying about a 24-h irrigation set (20 mm of water) at weekly intervals. The RDI treatments were initiated at $40 \%$ to $60 \%$ bloom, applied weekly, and ended at $40 \%$ to $60 \%$ veraison, with uniform irrigation to all plots thereafter. The treatments reduced the water applied by $25 \%(-25 \%), 33 \%(-33 \%)$, and $45 \%(-45 \%)$ from the control application (Table 1) by reducing run time during irrigation.

Initially, irrigation applications were tracked by constant communication with the grower. Starting in 2013, a pressure switch (Model PS-1; Decagon Devices, Pullman, WA) was installed in the drip tubing of the control treatment and connected to a data logger (EM50; Decagon Devices) to monitor the total time of each irrigation run. This was 
used to calculate the total water applied based on the emitter flow rate.

Weather. Climate data were collected from the Washington State University's AgWeatherNet system (http://weather.wsu.edu), Snipes weather station $\left(46^{\circ} 17^{\prime} 56.4^{\prime \prime},-119^{\circ} 54^{\prime}\right.$ $59.22^{\prime \prime}$ ) located less than $5 \mathrm{~km}$ from the research site. Total precipitation was measured, and growing degree days (base of $10^{\circ} \mathrm{C}, 1 \mathrm{Apr}$. to 31 Oct.) and grass reference evapotranspiration $\left(\mathrm{ET}_{\mathrm{o}}\right)$ were calculated. The accumulated growing degree days (GDD) increased seasonally: 1527 GDD accumulated in 2011, 1722 GDD in 2012, 1835 GDD in 2013, and 1938 GDD in 2014. The long-term average accumulated GDD for the Snipes station was 1749 GDD (2009-14); therefore, this trial encompassed a cool season (2011), an average season (2012), a warm season (2013), and a hot season (2014) as compared with long-term averages. Precipitation during the growing season was low and tended to be concentrated at the beginning and end of the growing season (Fig. 1).

Determining crop coefficients. The shaded area of the vineyard was used to calculate a crop coefficient for each treatment. A Paso panel (Battany, 2006) was used to measure the shaded area underneath the canopy. The Paso panel was constructed using a $1.5-\mathrm{m}$ solar panel (R-21; Powerfilm ${ }^{\circledR}$ Solar, Ames, IA) supported by an aluminum frame, wired to a digital multimeter (Sinometer, Shenzhen, China), and a temporary switch (item no. 31498; Ace Hardware, Oak Brook, IL). The maximum output of the solar panel was obtained by exposing the panel to full sun conditions at the beginning of each block. Shaded area readings were taken by placing the panel underneath the canopy

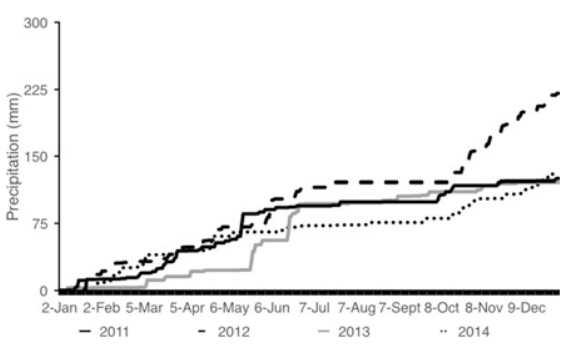

Fig. 1. Annual precipitation during 4 years of a deficit irrigation trial on 'Concord' grape in central Washington State, demonstrating low cumulative precipitation. Data from the AgWeather Net Snipes weather station (weather. wsu.edu).

Table 1. The total amount of irrigation applied $(\mathrm{mm})$ by treatment identification for grower control $(0)$ and three regulated deficit irrigation treatments $(-25 \%,-33 \%$, and $-45 \%$ of control) applied to 'Concord' grape from bloom through veraison for four growing seasons (2011-14).

\begin{tabular}{lcccr}
\hline Treatment (\% reduction) & 2011 & 2012 & 2013 & 2014 \\
\hline 0 & $\overline{-}^{\mathrm{z}}$ & 125.6 & 154.4 & 204.5 \\
$\approx 25$ & 108.2 & 94.0 & 148.0 & 120.9 \\
$\approx 33$ & 92.2 & 81.6 & 131.5 & 103.0 \\
$\approx 45$ & 76.0 & 68.7 & 107.5 & 81.3 \\
Start of treatment period & $20 \mathrm{June}$ & $3 \mathrm{June}$ & $22 \mathrm{May}$ & $27 \mathrm{May}$ \\
End of treatment period & $8 \mathrm{Sept}$ & $23 \mathrm{Aug}$. & 19 Aug. & 27 Aug. \\
Treatment period (d) & 80 & 81 & 89 & 92 \\
\hline
\end{tabular}

${ }^{\mathrm{z}}$ Total irrigation applied not available.

between the 10 sample vines in each plot (36 readings per treatment). The percent shaded area of the field was determined using the calculation method described by Battany (2006) and was subsequently used to calculate the crop coefficient $\left(K_{\mathrm{c}}\right)$ using the correlation equation of $K_{\mathrm{c}}$ to percent shaded area previously determined by Williams and Ayars (2005):

$$
\begin{aligned}
K_{\mathrm{c}}= & (0.017 \times \text { shaded percentage of field }) \\
& -0.008
\end{aligned}
$$

Soil moisture monitoring. The change in soil water content was monitored using a neutron probe (503 DR Hydroprobe ${ }^{\circledR}$; CPN International, Inc., Concord, CA). Neutron probe measurements were taken at $15-\mathrm{cm}$ increments to a depth of $90 \mathrm{~cm}$ in 2011, and $1400 \mathrm{~cm}$ in years 2012, 2013, and 2014 when neutron probe access tubes were reinstalled to take deeper measurement. Before the first treatment application, 16 polyvinyl chloride neutron probe access tubes were installed, one per plot, between sample vines two and nine. Each tube was located within 0.2 to $0.4 \mathrm{~m}$ away from a drip emitter on an $\approx 45^{\circ}$ diagonal from the drip tubing (Davenport et al., 2008). The tubes were made from $1-\mathrm{m}$ lengths in 2011 and $1.5-\mathrm{m}$ lengths in 2012, 2013, and 2014 of 5-cm-diameter pipe with a $2-\mathrm{mm}$ wall thickness (Ridgeline Pipe Manufacturing, Eugene, OR). Rubber stoppers were placed in the top of the tubes to prevent precipitation and debris accumulation.

The neutron probe was initially calibrated yearly using the laboratory method as outlined in the user manual (CPN International, 2011). The slope and intercept of the calibration equation were 2.757 and -0.054 , respectively, and were validated in the field by determining the gravimetric water content (Gardner, 1965) for each 15-cm depth at the time of access tube installation. These samples were used to calculated soil bulk density from the soil dry weight and volume (Gardner, 1965). The gravimetric water content was converted to volumetric and compared with the neutron probe measurements. The mean water content from the calibration soil samples and the neutron probe readings were 0.23 and $0.27 \mathrm{~cm}^{3} / \mathrm{cm}^{3}$ and a SE of 0.007 and 0.006 $\mathrm{cm}^{3} / \mathrm{cm}^{3}$, respectively. The correlation coefficient between the soil samples and the neutron probe measurements was 0.60 .

During 2011, measurements were taken on a weekly basis regardless of irrigation schedule

HortScience Vol. 52(3) March 2017 from June to October. However, in 2012, 2013, and 2014 measurements were taken within $24 \mathrm{~h}$ after the end of an irrigation event. The total soil depth measured $(140 \mathrm{~cm})$ was divided into two zones: the root zone $(\leq 60 \mathrm{~cm})$ and below the root zone $(>60 \mathrm{~cm})$ (Pradubsuk, 2008). The average volumetric water content (VWC) in each zone was determined from the VWC for each depth of surface $(0-60 \mathrm{~cm})$ and subsurface $(60-140 \mathrm{~cm})$ for each neutron probe site. Trends in the average VWC were evaluated by graphing the VWC by sampling date.

The fluctuation in soil water content was further investigated by separating the data by depth. The average VWC for each treatment was graphed verses time for each $15-\mathrm{cm}$ depth each year. In addition, the average VWC at each depth was plotted vs. time for each treatment and year to identify trends based on treatment. The depths $(15,30,45$, $60,75,90,105,120$, and $135 \mathrm{~cm})$ were plotted as a series for each year. Once plotted, four different sampling dates were identified, 1) the beginning of the treatment period (bloom), 2) about half way through the treatment period, 3 ) the end of the treatment period (veraison), and 4) after the final irrigation application of the season (October), and plotted with the percent VWC as a function of depth to illustrate seasonal changes in VWC.

Water balance. A basic water balance was calculated for the treatment period in 2014, the last year of study.

The water balance was based on the principal of the conservation of mass, thus, the change in soil water content is dependent on the water input into the system (precipitation, irrigation, etc.) and the water lost from the system (runoff, deep percolation, etc.) (Zeleke and Wade, 2012). The evapotranspiration from the 'Concord' grapevines and surrounding soil was calculated using the following equation

$$
\mathrm{ET}=\mathrm{P}+\mathrm{I}+\mathrm{U}-\mathrm{R}-\mathrm{D}-\Delta \mathrm{S}
$$

where $\mathrm{ET}=$ evapotranspiration, $\mathrm{P}=$ precipitation, $\mathrm{I}=$ irrigation, $\mathrm{U}=$ upward capillary rise, $\mathrm{R}=$ runoff, $\mathrm{D}=$ deep percolation, and $\triangle \mathrm{S}=$ the change is soil moisture storage (Zeleke and Wade, 2012). It was assumed that soil capillary rise and runoff were both negligible, due to the depth to the water table and the relatively low volumes of water applied, respectively. Deep percolation was a potential issue because the irrigation was concentrated along the drip line and the soil was well drained, but soil moisture measurements at deeper depths across all treatments did not show an increase in soil water content that would be indicative of deep percolation during the treatment period. Therefore, deep percolation was assumed to be zero. This is further supported by the continuously decreasing soil water content at deep depths.

The measured ET using Eq. [2] for each treatment was divided by $\mathrm{ET}_{\mathrm{o}}$, obtained from the AgWeatherNet (weather.wsu.edu) Snipes weather station to determine the $K_{\mathrm{c}}$ for each treatment. The water balance $K_{\mathrm{c}}$ values 
( $\left.K_{\text {c-water }}\right)$ were then compared with the $K_{\mathrm{c}}$ values calculated from the Paso panel readings ( $\left.K_{\text {c-Paso }}\right)$.

Vine measurements. Shoot length was measured weekly beginning at the three to four leaf stage. Each year, one shoot per sample vine in each plot was identified and tagged for measurements. The shoot length was determined by measuring from the base of the shoot to the growing tip. If a shoot was removed from the vine due to shoot thinning, tractor damage, etc., the shoot was not replaced. In addition, if the growing tip either died or was removed due to management practices it was noted and the shoot was measured to the point of injury. If a lateral bud began growing and surpassed the damaged or missing shoot tip, it became the terminus for the shoot length measurement. All shoots that were not removed from the vine due to damage were measured until mean shoot length became steady and more than half of the shoots no longer had growing tips. Shoot length measurements were transformed into growth rates by estimating a line, based on the plotted shoot lengths between 250 and 667 GDD $\left(10^{\circ} \mathrm{C}\right)$, using the Linest function in Excel (Microsoft Inc., Redmond, WA).

Fruit yield and quality were evaluated using standard methods. Fruit was harvested within 2 weeks of commercial harvest as indicated by the grower; harvest dates were 10 Oct. 2011, 3 Oct. 2012, 26 Sept. 2013, and 23 Sept. 2014. Total yield was assessed by harvesting a two vine equivalent (half of vine four, all of vine five, and half of vine six) from each 10 vine plot. All of the clusters from the two vine equivalent were picked, counted, and weighed using a digital shipping and receiving scale (Pelouze 4040;
Rubbermaid, Huntersville, NC). The total cluster count and total weight for the two vine sample were recorded and used to calculate the mean cluster count, mean cluster weight, fruit weight/vine, and total yield $(\mathrm{Mg} / \mathrm{ha})$ calculated given the vine density per hectare.

Enough fruit to fill a 3.8-L-sized plastic bag were randomly sampled from the picked fruit from each plot for analysis. The fruit was blended using a commercial laboratory blender (Waring model 31BL91; Waring Commercial, Torrington, CT) and $200 \mathrm{~mL}$ of pulp was frozen in a Kenmore heavy duty upright freezer (model no. 253; Sears, Roebuck and Co., Hoffman Estates, IL) at $-10{ }^{\circ} \mathrm{C}$ until the time of analysis and, for analysis, thawed until it attained ambient room temperature. Total soluble solids (TSS, ${ }^{\circ}$ Brix) were determined using a digital refractometer (model 300016; Kernco Instruments Co., El Paso, TX). Titratable acidity (TA) and $\mathrm{pH}$ were determined using an auto titrator (DMS Titrino Metrohm; Brinkmann Instruments, Inc., Riverview, FL) and total color and phenolics were analyzed with a spectrophotometer (Shimadzu ultraviolet-1800; Shimadzu Corporation, Nakagyo-ku, Kyoto) using standard methods (Iland, 2004).

Pruning weight was collected after the 2013 and 2014 field seasons, but not during the first two field seasons (2011 and 2012) as the grower pruned before pruning weight could be sampled. Vines two to eight in each treatment area were pruned at $30 \mathrm{~cm}$ below the trellis wire to simulate minimal pruning by mechanical operations. The shoots removed from each vine were collected into 18.9-L buckets and weighed using a digital fish scale (Berkley, Spirit Lake, IA).

Statistics. The raw data were analyzed using SAS 9.4 version 6.2 .9200 (SAS
Institute Inc., Cary, NC). The variance in the data (analysis of variance) was tested using Proc GLM with the main effects of year and treatment and the interactive effect of year $\times$ treatment. Also, the data were sorted by year and analyzed again to eliminate the effect of year-to-year variation. The DuncanWaller mean separation test was run to determine the degree of separation between the treatment means.

\section{Results}

Canopy size. Paso panel measurements provided a relative indication of total canopy size. Lower values indicated a denser canopy, whereas high values indicated a small or open canopy. These measurements provided a unique look into canopy variability. The Paso panel measurements ranged from 0.02 to 0.95 amps indicating that the 'Concord' canopy was highly variable (data not shown). This was likely due to vineyard age (21 years) and vine replacement, resulting in vines of different ages and to the natural variability in vine canopies.

Although there was a high degree of variability in the shaded area readings during the treatment period (bloom through veraison), the sample size was adequate (nine measurements per plot, total of 36 measurements per treatment) to minimize the effects of canopy variability on the $K_{\mathrm{c}}$. The maximum $K_{\mathrm{c}}$ values were highest in 2011 (Fig. 2). In 2011 , the $-45 \%$ treatment had a grass reference $K_{\mathrm{c}}$ of 0.78 , whereas the control, $-25 \%$, and $-33 \%$ were $0.76,0.76$, and 0.77 respectively. These results were not representative of the treatments applied because it was the first treatment year in a perennial crop. In addition, the canopy was fully

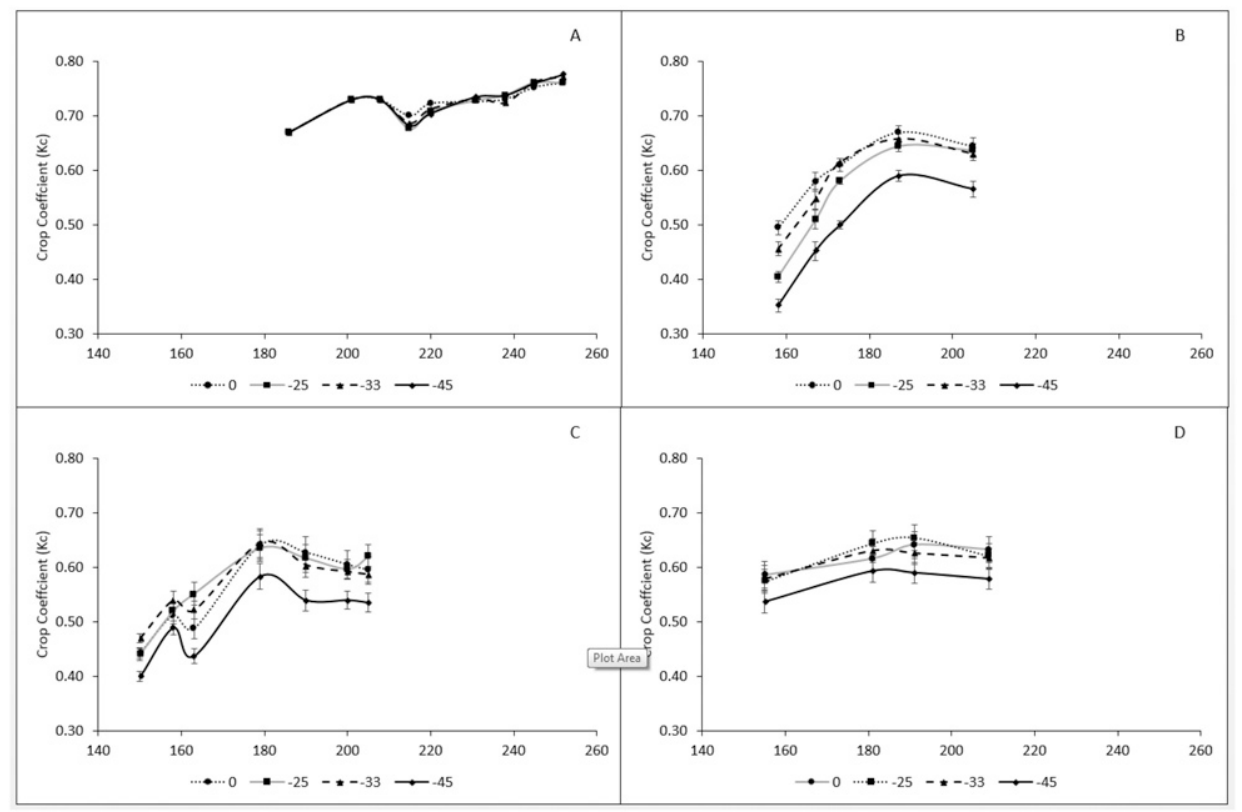

Fig. 2. 'Concord' grass reference $\left(\mathrm{ET}_{\mathrm{o}}\right)$ crop coefficients $\left(K_{\mathrm{c}}\right)$ as determined by percent shaded area measurements for each treatment (high, moderate, low, and very low) during the treatment period between $\approx 50 \%$ bloom and 50\% veraison in (A) 2011, (B) 2012, (C) 2013, and (D) 2014. Error bars indicate one sD (not included in 2011). 
established before the imposition of water deficits. In 2012, the highest $K_{\mathrm{c}}$ value was from the control treatment $(0.67)$, the $-25 \%$ and $-33 \%$ treatments were closely grouped ( 0.64 and 0.66$)$, whereas the $-45 \%$ treatment was 0.59 and statistically lower $(P<0.01)$. This trend continued through the next two seasons. The very low treatment always had the lowest maximum $K_{\mathrm{c}}$ value, at 0.58 and 0.59 for 2013 and 2014, whereas the other treatments averaged 0.65 (Fig. 1) and were not statistically different from each other $(P<0.01)$.

The vines reached their maximum $K_{\mathrm{c}}$ values by 9 July in all treatment years, with the exception of 2011. After 9 July the values began to decline slightly. The high, moderate, and low treatments were very closely grouped, indicating very similar canopy size between the treatments; however, the very low treatment always had lower values than the rest of the treatments (Fig. 2).

The total accumulated $\mathrm{ET}_{\mathrm{o}}$ during the treatment period (bloom to veraison) was $461,466,515$, and $535 \mathrm{~mm}$ in 2011, 2012, 2013, and 2014, respectively. The timing of the treatment period shifted from year to year because of differences in GDD (base $10^{\circ} \mathrm{C}$ ) accumulation before the treatment period. In 2011, the treatment period began on 20 June at 283 GDD. The treatment period began earlier in 2012, on 3 June at 279 GDD. The final two seasons, 2013 and 2014, began even earlier, on 22 May and 27 May at 248 and 262 GDD, respectively. This indicated that bloom, the beginning of our treatment period, occurred once $\approx 250$ GDD had accumulated.

The accumulated $\mathrm{ET}_{\mathrm{c}}$ for the treatment period in 2011 , as determined by multiplying the $K_{\mathrm{c}}$ by the $\mathrm{ET}_{\mathrm{o}}$, was not statistically different by treatment (Table 2). As the trial progressed, $\mathrm{ET}_{\mathrm{c}}$ showed separation, but there was no statistical difference between the very low treatment and the other treatments with a difference between the high and very low treatment of $44 \mathrm{~mm}$ ( $15 \%$ reduction), $28 \mathrm{~mm}$ (10\% reduction), and $26 \mathrm{~mm}$ (5\% reduction), in 2012, 2013, and 2014, respectively. This corresponded with Paso panel measurements indicated by a reduced canopy size from year to year in the very low treatment. For example, the difference in the $K_{\text {c-Paso }}$ between the high and very low treatments in 2014 indicated a $6 \%$ reduction in canopy size.

Soil water content. In 2011, the soil water content in the root zone fluctuated greatly from the initial soil water content in the spring (Fig. 3A). Generally, there was a decrease in soil water content across the treatment period for the moderate to very low treatments. This trend continued after the treatment period had ended and resulted in a loss of $25 \%$ to $35 \%$ of the initial soil water content. However, at the end of the season the high treatment had a $25 \%$ higher soil water content than the initial measurement. By 26 July 2011, $36 \mathrm{~d}$ after the treatments were started, the high and moderate treatments showed increased soil water content and remained consistent for another $12 \mathrm{~d}$ when soil water content in the moderate treatment

Table 2. The accumulated crop-specific evapotranspiration $\left(\mathrm{ET}_{\mathrm{c}}\right)(\mathrm{mm})$, as calculated by multiplying the grass reference evapotranspiration $\left(\mathrm{ET}_{\mathrm{o}}\right)$ and the Paso panel shaded area method crop coefficient $\left(K_{\mathrm{c}}\right)$, by treatment (control, $-25 \%,-33 \%$, and $-45 \%$ ) from the beginning (bloom) to the end (veraison) of the treatment period for all four treatment years, along with the average $\mathrm{ET}_{\mathrm{c}}$ by treatment and year.

\begin{tabular}{llllll}
\hline $\begin{array}{l}\text { Treatments } \\
\text { (\% reduction) }\end{array}$ & 2011 & 2012 & 2013 & 2014 & Avg \\
\cline { 2 - 6 } & 325 & 294 & 291 & 338 & $312 \mathrm{a}$ \\
-25 & 324 & 281 & 295 & 337 & $309 \mathrm{a}$ \\
-33 & 325 & 287 & 291 & 333 & $309 \mathrm{a}$ \\
-45 & 325 & 250 & 263 & 312 & $288 \mathrm{~b}$ \\
Average & $325 \mathrm{a}$ & $278 \mathrm{~b}$ & $285 \mathrm{~b}$ & $330 \mathrm{a}$ & \\
\hline
\end{tabular}

Mean separation of the average accumulated $\mathrm{ET}_{\mathrm{c}}$ by treatment and by year using Duncan's multiple range test at $P \leq 0.05$ as indicated by lowercase letters.
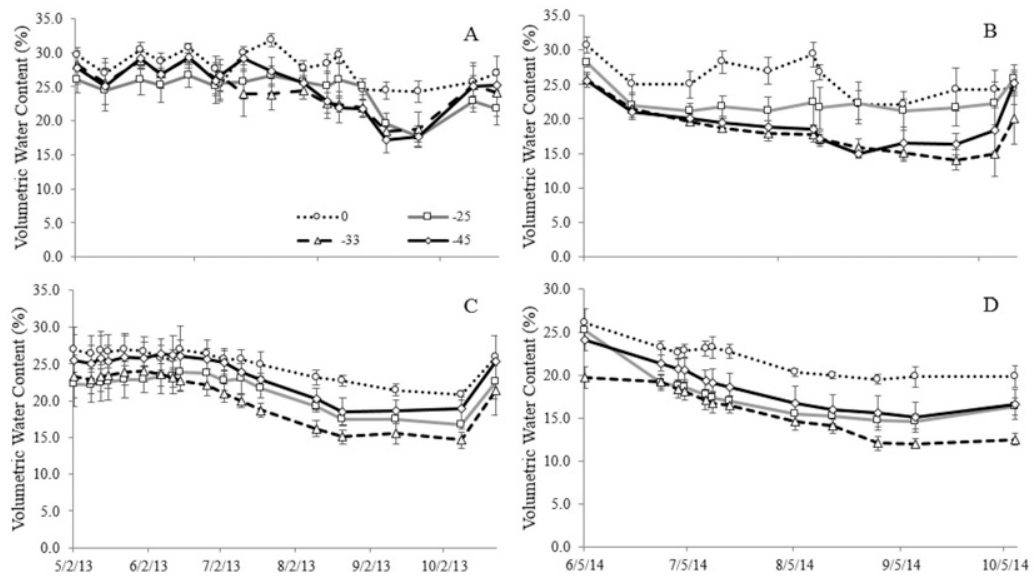

Fig. 3. Average soil volumetric water content $(\%)$ by treatment $(0 \%, 25 \%, 33 \%$, and $45 \%$ reduction from the grower control) in the root zone in (A) 2011 and (B) 2012 and below the root zone in (C) 2011 and (D) 2012. Error bars indicate one SD.

decreased to the level of the low and very low treatments. The high treatment had measurably greater soil moisture than the rest of the treatments through the end of the season. All the treatments, except for the high treatment, decreased in soil water content by $35 \%$ to $40 \%$ over the season (Fig. 3A).

The fluctuations in soil water content were not as large below the root zone (Fig. 3C). In the first year (2011), the high and very low treatments had higher soil water content than the moderate and low treatments. All the treatments converged and were not statistically different for two additional measurements $36 \mathrm{~d}$ after treatments began with the exception of the high treatment when the soil water content increased $21 \mathrm{~d}$ later and was maintained throughout the remainder of the 2011 season.

The subsequent years of the trial exhibited the same general trends as 2011 (Figs. 3B and $\mathrm{D}$ and $4 \mathrm{~A}-\mathrm{D})$. There was a decrease in soil water content in both the root zone and below the root zone throughout the trial period and the rest of the season. There was an exception in 2013 when there was a small increase in soil moisture at the last measurement (Fig. 4A and C), indicating a deep percolation event.

Fluctuations in soil water content were more intense in the root zone than below the root zone. It took longer to develop the same percentage loss in soil VWC below the root zone than in the root zone. For example, on
13 July 2012, the low treatment VWC in the root zone had decreased by $\approx 35 \%$, whereas it had only decreased by just under $20 \%$ below the root zone (Fig. 3B and D).

Across all years and treatments, there was a greater degree of variation in VWC in the 0 to $15 \mathrm{~cm}$ and the 15 to $30 \mathrm{~cm}$ depths than below $30 \mathrm{~cm}$ (data not shown), attributable to direct evaporative loss from the soil surface and water uptake from vine roots, which are predominantly near the surface. As soil depth increased, variability decreased to a moderate level between 45 and $60 \mathrm{~cm}$. Below $60 \mathrm{~cm}$, the VWC decreased steadily across the season (Figs. 3B and D, 4B and D, and 5A-L), with the exception of some late season (October) irrigation applications that wetted to a depth of $135 \mathrm{~cm}$ in 2013 and $105 \mathrm{~cm}$ in 2014. The high treatment maintained the highest VWC throughout the season down to $120 \mathrm{~cm}$ (Fig. 5A, E, and I). However, at the $135-\mathrm{cm}$ depth, the high treatment did not differ from the other treatments, indicating that the $135-\mathrm{cm}$ depth was likely below most of the vine roots.

Water balance. The $K_{\mathrm{c}-w a t e r}$ was calculated for the period between each irrigation event during the treatment period (bloom to veraison). The $K_{\text {c-water }}$ for the high treatment had an average value of 0.49 , which is 0.13 lower than the $K_{\mathrm{c}-P a s o}$ for the entire treatment period. All of the other treatments had $K_{\mathrm{c}-}$ water values with a difference greater than 0.10 from the $K_{\text {c-Paso }}$ values (Table 3 ), with 

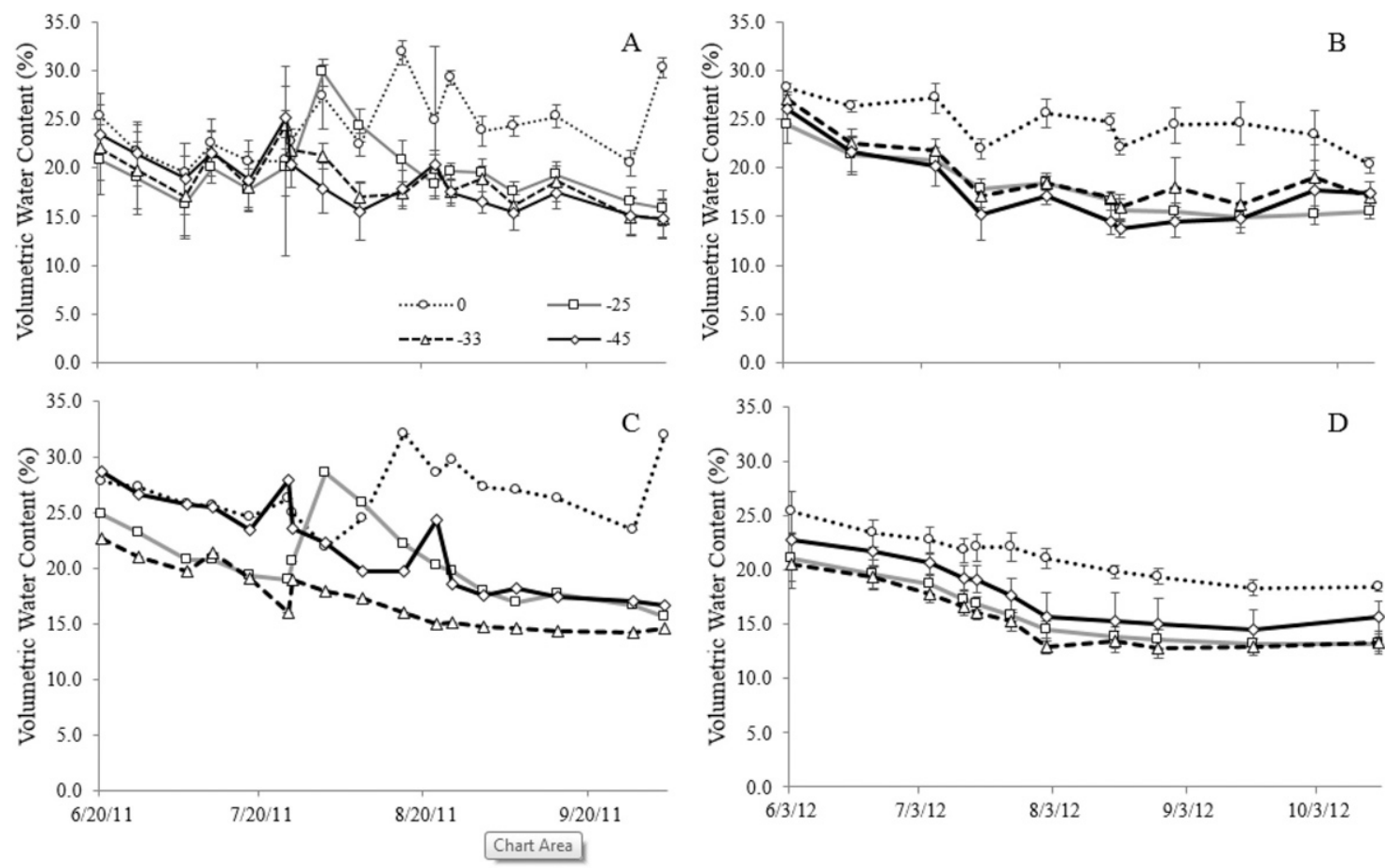

Fig. 4. Average soil volumetric water content (\%) by treatment $(0 \%, 25 \%, 33 \%$, and $45 \%$ reduction from the grower control) in the root zone in (A) 2013 and (B) 2014 and below the root zone in (C) 2013 and (D) 2014 (D). Error bars indicate one sD.
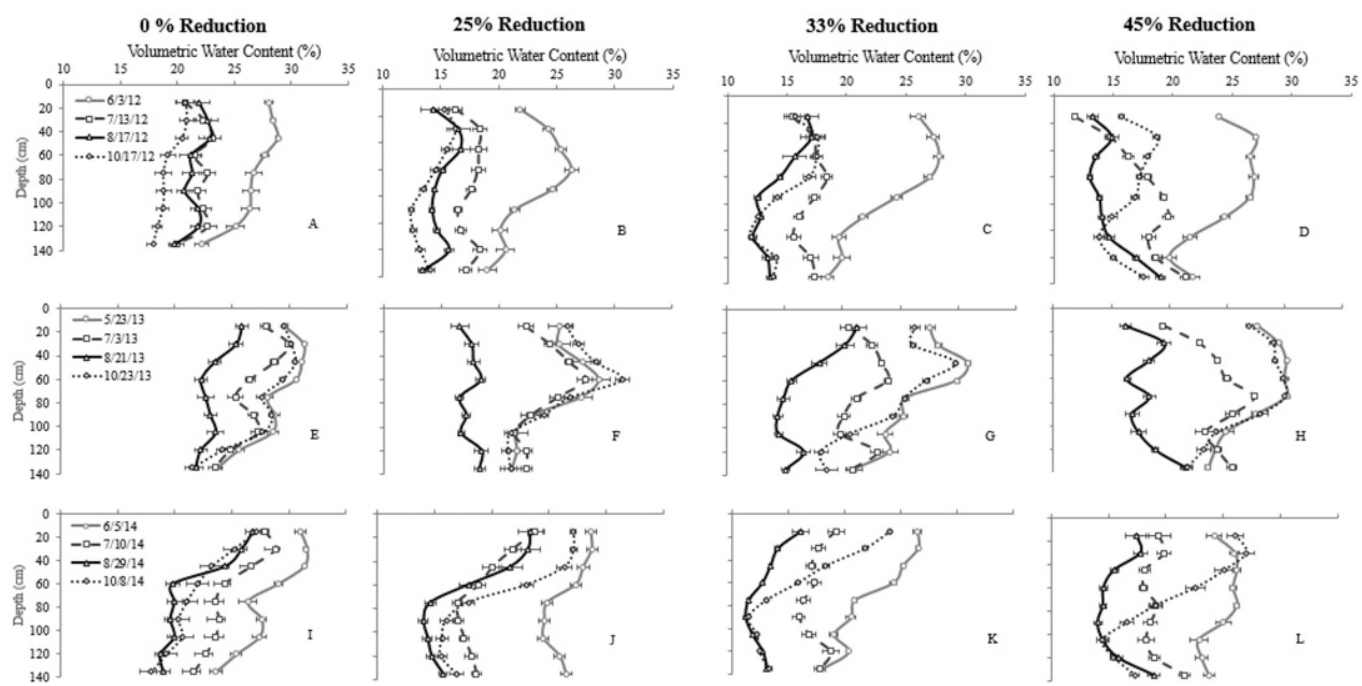

Fig. 5. Average volumetric water content (\%) through the entire soil profile $(0-135 \mathrm{~cm})$ by treatment $[$ Control, $0 \%$ reduction $(\mathbf{A}, \mathbf{E}$, and $\mathbf{I}), 25 \%$ reduction in applied water $(\mathbf{B}, \mathbf{F}$, and $\mathbf{J}), 33 \%$ reduction in applied water $(\mathbf{C}, \mathbf{G}$, and $\mathbf{K})$, and $45 \%$ reduction in applied water $(\mathbf{D}, \mathbf{H}$, and $\mathbf{L})]$ at the beginning (bloom), half way through, and at the end of the treatment period (veraison), and at the end of the irrigation season (October) for each treatment in years (A-D) 2012, (E-H) 2013, and (I-L) 2014. Error bars indicate one SD.

the exception of the low treatment, which was within 0.06 of the corresponding $K_{\text {c-Paso }}$ value.

There were two short periods when the water balance resulted in a negative number, which is not possible. After reviewing the data for errors and finding none, it was assumed that the difference in soil VWC was due to natural variation in drying down after an irrigation event. To correct the negative result, the change in VWC of the date resulting in a negative value was averaged with the next closest sampling date. The irrigation applied and precipitation were added together for the two dates and used to calculate a new $\mathrm{ET}_{\mathrm{c}}$. The resulting value corrected the negative result previously obtained.

Shoot growth and pruning weight. Shoot growth rate differed by year, but not by treatment or the interactive effect of year $x$ treatment. The only year where shoot growth rate differed by treatments was $2011(P=0.0184)$. The means for the high through the very low treatments in 2011 were $0.87 \mathrm{ab}, 0.65 \mathrm{~b}, 0.72 \mathrm{~b}$, and $1.13 \mathrm{a}$, respectively, where the letters that are different from each other indicate a statistically significant difference at the 0.05 level using the Duncan-Waller mean separation. The lack of difference in shoot growth rate was likely because the majority of shoot growth had occurred before or at the beginning of the treatment period before significant soil water deficits had developed (Fig. 6). The difference that occurred in 2011 was likely caused by differences in soil moisture before treatment establishment. Even though shoot length is one of the first indicators 
of water stress, total shoot length was unaffected.

In 2013, the average pruning weight per vine across all treatments was $0.20 \mathrm{~kg} / \mathrm{vine}$, with $0.28,0.19,0.17$, and $0.14 \mathrm{~kg} / \mathrm{vine}$ in the high, moderate, low, and very low treatments, respectively, and the high treatment had significantly more mass than the other treatments. In 2014, the average pruning weight per vine across all treatments was lower than previous years, $0.13 \mathrm{~kg} / \mathrm{vine}$, and there were no statistical differences by treatment.

Fruit yield and quality. There were no statistical differences in cluster weight or number (data not given), nor the fruit quality factors TSS, pH, TA, or color by treatment (Table 4). The biggest source of variability in yield was year-to-year differences $(P=$ $0.0002)$. Therefore, yields were sorted by year to determine if the treatments had any significant impact on yield. There were no significant differences in yield by treatment during the trial period, except for 2012 (Fig. 7). Average yields across all treatments in 2011, 2012, 2013, and 2014 were 20.0, $13.5,24.2$, and $21.6 \mathrm{Mg} / \mathrm{ha}$, respectively. The yield decline in 2012 could have been related to treatments or to the cool weather in the 2011 growing season. In 2012, there was a significant difference between the control treatment $(19.2 \mathrm{Mg} / \mathrm{ha})$ and $-45 \%$ treatment (7.5 Mg/ha) (Fig. 7). All fruit quality parameters were statistically different by year, but not by treatment or treatment $\times$ year (Table 4 ).

\section{Discussion}

With the exception of the first year (2011), each year there was a gradual decrease in soil water content over the season in both the root zone and below the root zone, which was likely a result of $\mathrm{ET}_{\mathrm{c}}$ and decreasing water applications (RDI) leading to an increase in water extraction from deeper in the soil profile. At the beginning of the treatment period, all treatments had the same soil VWC (Fig. 5A-L). Soil VWC was higher in the root zone $(<60 \mathrm{~cm})$ at the beginning of the treatment period than below the root zone $(>60 \mathrm{~cm})$, likely from overwinter precipitation and early season irrigation applications, or because the soil in the root zone had a greater water-holding capacity. By the end of the treatment period, the root zone soil moisture was about the same VWC as below the root zone, likely due to plant uptake and the deficit treatments. The degree of dry down was less in the high treatment (Fig. 5A, E, and I) and the VWC curves remain tightly clustered together indicating

Table 3. The average grass reference $\left(\mathrm{ET}_{\mathrm{o}}\right)$ crop coefficients $\left(K_{\mathrm{c}}\right)$ for each treatment (high, moderate, low, and very low) as determined by shaded area measurement (Paso) and water balance calculations (water balance) during the treatment period in 2014 (5 June to 29 Aug.).

\begin{tabular}{lccccc}
\hline & High & Moderate & Low & Very low & $\begin{array}{c}\text { Avg (all } \\
\text { treatments) }\end{array}$ \\
\hline Paso & 0.62 & 0.62 & 0.61 & 0.58 & $0.61^{*}$ \\
Water balance & 0.49 & 0.43 & 0.55 & 0.45 & $0.48^{*}$ \\
Difference $^{\mathrm{z}}$ & 0.13 & 0.19 & 0.06 & 0.13 & 0.13 \\
\hline
\end{tabular}

${ }^{\mathrm{z}}$ Determined by subtracting the Water balance from the Paso values.

${ }^{*}$ Significant difference at $\alpha=0.05$.

small changes in VWC over the treatment period. However, as the amount of water applied decreased, there was a widening of the gap between the initial and end of treatment VWC in the moderate, low, and very low treatments (Fig. $5 \mathrm{~B}-\mathrm{D}, \mathrm{F}-\mathrm{H}$, and $\mathrm{J}-\mathrm{L}$ ).

Soil VWC was also measured at the end of the irrigation season to determine if soil VWC would return to pretreatment levels. In 2013, the soil profile was refilled to pretreatment levels in all treatments (Fig. 5E$\mathrm{H})$. However, the profile was not completely refilled in 2012 and 2014. In 2012, the VWC at the end of the season (October) was the lowest of all sample points in the high treatment and refilled to roughly the midtreatment measurement in the top 40 to $60 \mathrm{~cm}$ of depth in the moderate, low, and very low treatments. However, the VWC remained equal to or less than the VWC at the end of the treatment period (veraison) through the rest of the profile (Fig. 5A-D). In 2014, the top $60 \mathrm{~cm}$ of the profiles were refilled to about the same levels as the initial (bloom) measurement in the moderate, low, and very low treatments, but the high treatment remained at the same level as at veraison measurement (Fig. 5I-L). Thus, late season irrigation was generally successful at refilling the root zone $(0-60 \mathrm{~cm})$, but winter precipitation and early season irrigation was necessary to completely refill the soil profile to a $135-\mathrm{cm}$ depth.

Vines under increasingly severe RDI are forced to extract more stored soil water and from deeper depths than plants under full irrigation, resulting in a loss of stored soil water and a gradual increase in plant water stress (Fereres and Soriano, 2007). However, in this study, the severity of the deficit did not necessarily correlate with the reduction in VWC. For example, in 2012, 2013, and 2014,
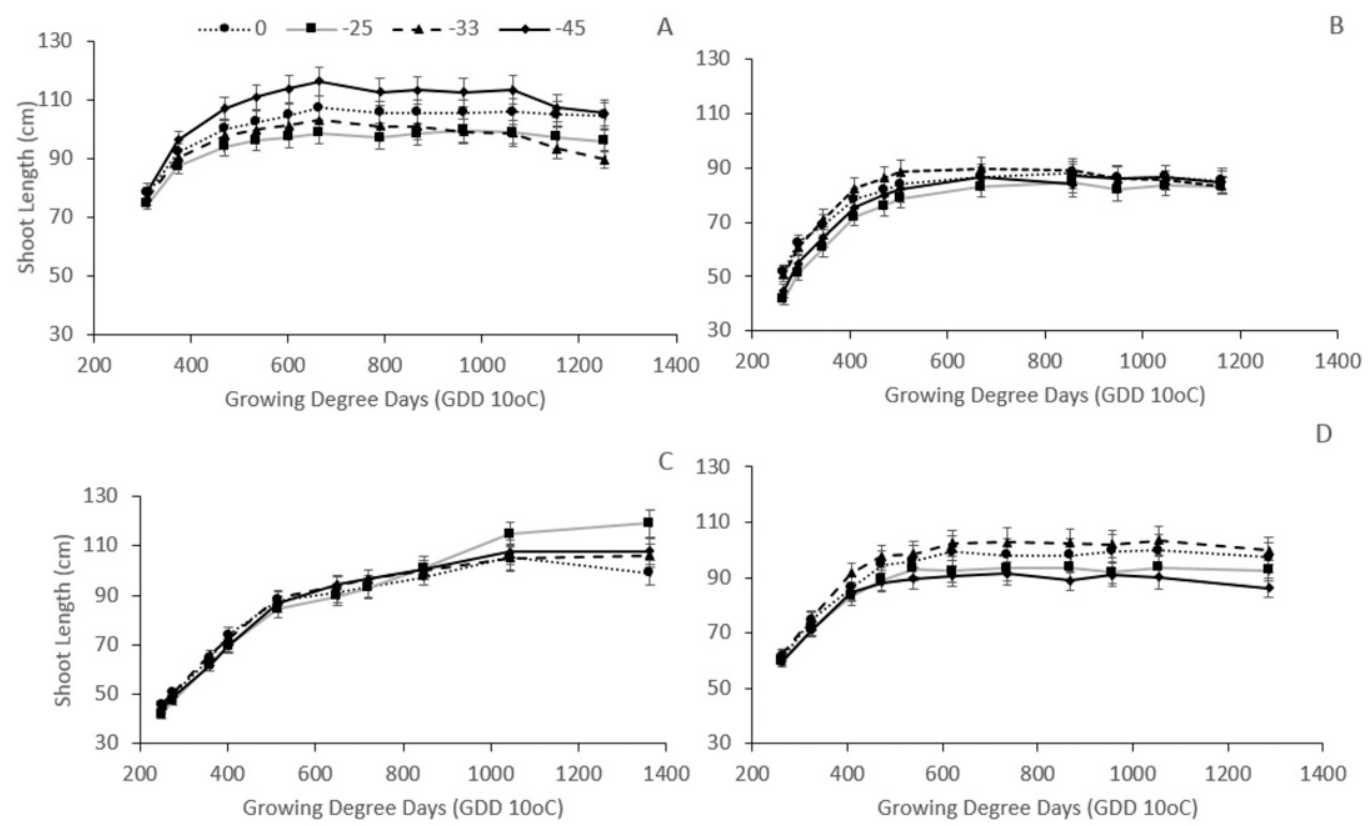

Fig. 6. Total shoot length over treatment period, from bloom to veraison. Treatments show irrigation amount of irrigation reduction during this period of control ( 0 reduction) or $-25 \%,-33 \%$, or $-45 \%$ in (A) 2011, (B) 2012, (C) 2013, and (D) 2014. Error bars indicate one SD. 
Table 4. 'Concord' berry quality was measured by total soluble solids concentration ( $\left.{ }^{\circ} \mathrm{Brix}\right)$, $\mathrm{pH}$, titratable acidity (TA) $\left(\mathrm{g} \cdot \mathrm{L}^{-1}\right.$ tartaric acid), color (absorbance at $\left.520 \mathrm{~nm}\right)$, and total phenolics (absorbance at $280 \mathrm{~nm}$ ). There were no statistical differences between measured parameters by treatment.

\begin{tabular}{lllcccc}
\hline & & ${ }^{\circ}$ Brix & pH & TA & A520 & A280 \\
\hline Year & 2011 & 15.4 & 3.45 & 7.18 & 0.086 & 0.22 \\
& 2012 & 17.2 & 3.59 & 4.49 & 0.047 & 0.21 \\
& 2013 & 17.9 & 3.71 & 4.22 & 0.069 & 0.24 \\
\multirow{3}{*}{ Treatment } & 2014 & 15.0 & 3.64 & 5.31 & 0.047 & 0.24 \\
& High & 16.2 & 3.63 & 5.43 & 0.064 & 0.23 \\
& Moderate & 16.5 & 3.58 & 5.44 & 0.059 & 0.22 \\
& Low & 16.2 & 3.60 & 5.04 & 0.063 & 0.24 \\
Level of significance $(P)$ & Very low & 16.6 & 3.58 & 5.29 & 0.063 & 0.23 \\
& Year & $<0.0001$ & $<0.0001$ & $<0.0001$ & $<0.0001$ & 0.0624 \\
& Treatment & 0.5905 & 0.5021 & 0.1760 & 0.7415 & 0.7778 \\
& & & & & &
\end{tabular}

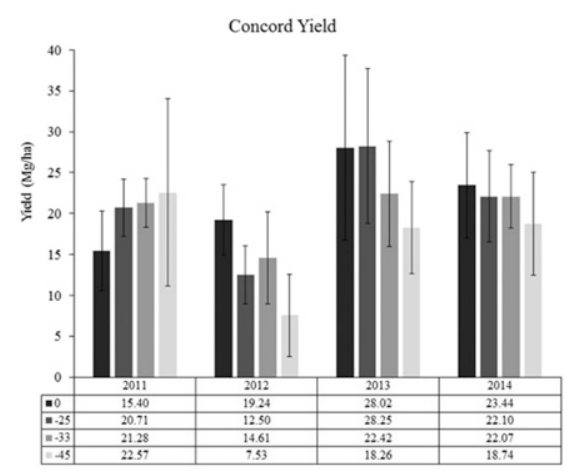

Fig. 7. 'Concord' yield in $\mathrm{Mg} / \mathrm{ha}$ by year $(2011$, 2012,2013 , and 2014) and treatment $(0 \%, 25 \%$, $33 \%$, and $45 \%$ irrigation reduction from grower control from bloom through veraison). Error bars indicate one SD.

the moderate and low treatments, which reduced the amount of water applied by $\approx 25 \%$ and $33 \%$, regularly lost an equal or greater amount of soil water than the very low treatment, which was reduced by $\approx 45 \%$ (Figs. 3B and D and 4B and D).

Yield decreased from 2011 to 2012 as well as with increased severity of treatment in 2012, likely due to plant stress response from water deficits. However, there were no significant differences in yield by treatment in 2013 or 2014 . This indicated that, despite the repeated application of water deficits on the same vines year after year over a limited period (bloom to veraison), the lowest water application was sufficient to maintain the health of the vine despite initial decreases in yield. If the reduced water application was insufficient to maintain vine heath the vines would have experienced a decrease in yield each year, increasing in severity as the trial progressed, which was the opposite of what was observed. Previous research indicates that grapevines redistribute roots both vertically and horizontally in response to soil moisture (Celette et al., 2008). The soil water content was very high throughout the season in the high treatment, when irrigation was reduced the vines under moderate, low, and very low treatments likely only had a fraction of their roots available to take up water as suggested by the findings of Celette et al. (2008). It is likely that after the 2 nd year of deficit applications the vine roots had adapted to the smaller wetted soil volume. This is further supported by the work of Soar and Loveys (2007), who found when changing from sprinkler to drip irrigation, 'Cabernet Sauvignon' and 'Shiraz' grape roots concentrated under the drip line.

TSS was the most important quality factor for 'Concord' growers and was the parameter used to determine the acceptability of grapes at local processers. The minimum standard for TSS was $15{ }^{\circ}$ Brix and fruit from all 4 years, regardless of treatment, met that standard (Table 4). In addition, the values of the quality parameters observed in this study were consistent with historical values presented by Johnson and Nagel (1976). Thus, our results suggest that 'Concord' berry quality was not directly affected by reducing irrigation between bloom and veraison.

\section{Conclusion}

RDI is common in other sectors of grape production, but not in 'Concord' grape production. This research shows that the application of an RDI strategy has the potential to reduce total water use without erate treatment would potentially save $25 \%$ to $50 \%$ of water currently applied from bloom to veraison, the low treatment could save $40 \%$ to $65 \%$, and the very low treatment would provide the greatest savings. However, initial yield losses of up to $60 \%$ in the first several years of irrigation reduction are likely too great a negative economic impact. However, under the treatment conditions these plants seem to have adapted over time. Therefore, to minimize short-term losses, these results suggest to gradually step down reductions in water application rates over several years until the total desired reduction is obtained.

Battany, M. 2006. Crop coefficients-Paso panel San Luis Obispo County. 10 May 2016. <http:// cesanluisobispo.ucanr.edu/Viticulture/Paso_Panel/>.

Celette, F., R. Gaudin, and C. Gary. 2008. Spatial and temporal changes to the water regime of a Mediterranean vineyard due to the adoption of cover cropping. Eur. J. Agron. 29(4):153-162. robe operating manual. CPN International Inc., Concord, CA.

Cuykendall, C.H., G.B. White, B.E. Schaffer, A.N Lasko, and R.M. Dunst. 1999. Economics of drip reducing berry quality. Adopting the mod-

\section{Literature Cited}

CPN International Staff. 2011. 503 DR Hydrop- irrigation for juice grape vineyards in New York State. R. B. 99-01, Cornell University, Ithaca, NY. Davenport, J.R., R.G. Stevens, and K.M. Whitley. 2008. Spatial and temporal distribution of soil moisture in drip-irrigated vineyards. HortScience 43:229-235.

Elsner, M.M., L. Cuo, N. Voisin, J.S. Deems, A.F. Hamlet, J.A. Vano, K.E.B. Mickelson, S.-Y. Lee, and D.P. Lettenmaier. 2010. Implications of 21st century climate change for the hydrology of Washington State. Clim. Change 102:225-260.

Evans, R.G., S.E. Spayd, R.L. Wample, M.W. Kroeger, and M.O. Mahan. 1993. Water use of Vitis vinifera grapes in Washington. Agr. Water Mgt. 23:109-124.

Fereres, E. and M.A. Soriano. 2007. Deficit irrigation for reducing agricultural water use. J. Expt. Bot. 58(2):147-159.

Fischer, R.A. and N.C. Turner. 1978. Plant productivity in the arid and semiarid zones. Annu. Rev. Plant Physiol. 29:277-317.

Gardner, W.H. 1965. Water content, p. 82-127. In: R.C. Dinauer (ed.). Methods of soil analysis. Agronomy. Amer. Soc. Agron. Inc., Madison, WI.

Hoheisel, G. and M. Moyer. 2016. Pest management guide for grapes in Washington-2016. EB0762. Washington State University, Pullman, WA.

Iland, P. 2004. Chemical analysis of grapes and wine: Techniques and concepts. Patrick Iland Wine Promotions PTYLTD, Campbelltown, Australia.

Johnson, T. and C.W. Nagel. 1976. Composition of central Washington grapes during maturation. Amer. J. Enol. Viticult. 27:15-20.

Kriedemann, P.E. and I. Goodwin. 2003. Regulated deficit irrigation and partial rootzone drying: An overview of principles and applications. CSIRO Land and Water Australia, Canberra, Australia.

Morris, J.R. and D.L. Cawthon. 1982. Effect of irrigation, fruit load, and potassium fertilization on yield, quality, and petiole analysis of Concord (Vitis labrusca L.) grapes. Amer. J. Enol. Viticult. 33:145-148.

Morris, J.R., S.E. Spayd, and D.L. Cawthon. 1983a. Effects of irrigation, pruning severity and nitrogen levels on yield and juice quality of Concord grapes. Amer. J. Enol. Viticult. 34:229-233.

Morris, J.R., S.E. Spayd, and D.L. Cawthon. 1983b. Influence of drip irrigation on "Concord" grapes. Ark. Farm Res.

Moyer, M., T. Peters, and R. Hamman. 2013. Irrigation basics and strategies for eastern Washington grape production. EM061E. Washington State University, Pullman, WA.

Pradubsuk, S. 2008. Uptake and partitioning of mineral nutrients in Concord grape. Washington State Univ., Pullman, PhD Diss. 3370414.

Soar, C.J. and B.R. Loveys. 2007. The effect of changing patterns in soil-moisture availability on grapevine root distribution, and viticultural implications for converting full-cover irrigation into a point-source irrigation system. Austral. J. Grape Wine Res. 13:2-13.

Washington Department of Ecology. 2001. 2001 drought response. Publication no. 01-11-017, Olympia, WA.

Washington Department of Ecology. 2015. Ecology responding to the 2015 statewide drought. Publication no. 10-11-002, Olympia, WA.

Williams, L.E. and J.E. Ayars. 2005. Grapevine water use and the crop coefficient are linear functions of the shaded area measured beneath the canopy. Agr. For. Meteorol. 132:201-211.

Zeleke, K.T. and L.J. Wade. 2012. Evapotranspiration estimation using soil water balance, weather and crop data. In: A. Irmak (ed.). Evapotranspiration: Remote sensing and modeling. InTech, Rijeka, Croatia. 